\title{
Pengaruh Pendekatan Metode Role Playing dalam Mengurangi Perilaku Agresif Anak Kelompok B di TK Budhi Luhur Rumbai Pekanbaru
}

\author{
Sean Marta Efastri \\ Universitas Lancang Kuning \\ Email: seanmarta@unilak.ac.id
}

\begin{abstract}
Abstrak:
Bentuk perilaku agresif dibagi menjadi dua yaitu agresif verbal dan agresif non verbal. Agresif verbal antara lain mengancam temannya, menyakiti perasaan temannya, dll. Agresif non verbal atau fisik berupa serangan yang melukai temannya seperti memukul, mencubit, mendorong, dll). Penelitian ini bertujuan untuk mengetahui Pengaruh dari metode Role Playing dalam mengurangi perilaku agresif anak kelompok B di TK Budhi Luhur Rumbai Pekanbaru. Penelitian ini dilaksanakan pada semester genap bulan Maret 2018/2019. Desain penelitian ini yang digunakan adalah The One Group Pretest-Posttest Design. Jumlah populasi terdiri dari 16 anak. Teknik pengambilan sampel penelitian ini dengan cara total sampling. Pengumpulan data dilakukan melalui Pretest, Posttest, dan lembar observasi. Hal ini dapat dibuktikan dari hasil observasi sebelum tindakan diperoleh presentase 29,75 dan sesudah perlakuan berubah menjadi 16,44. Dari hasil penelitian dapat disimpulkan bahwa terdapat pengaruh yang signifikan sebelum diberikan perlakuan dengan sesudah diberikan metode role playing dalam mengurangi perilaku agresif anak kelompok B di TK Budhi Luhur Rumbai Pekanbaru.
\end{abstract}

\section{Kata Kunci : Metode Role Playing, Perilaku Agresif Anak.}

\begin{abstract}
:
Form of aggressive devided into two that is verbal aggressive and non verbal aggressive. Verbal aggressive among others threatening his friends, hurting feeling of his friends. Non verbal aggressive or physical is an attack that hurts his friends like punching, pushing. This research is to knowing the influence from role playing method in reducing aggressive behavior children group B in Budhi Luhur kindergarten Rumbai Pekanbaru. This research did in the even semester in march 2018/2019. The design of this research used is The One Group Pretest-Posttest Design. Total of the population are is children. Technique of the taking sempel from this research is with total sampling. Data collection is done through pretest, posttest and observation sheet. This thing can be prove from the results observation before action obtaine percent 29,75 and after the treatment changes become 16,44. From the result of the research it can be concluded that there is asignificant influence before treatment with after role playing method treatment in reducing aggressive behavior B children group in Budhi Luhur Kindergarten Rumbai Pekanbaru.
\end{abstract}

Key Words : Role Playing Method, Children Aggressive Behavior 


\section{PENDAhULUAN}

Pembelajaran tentang sikap, perilaku dan bahasa yang baik. Masalah perilaku merupakan masalah yang sangat penting bagi pertumbuhan, perkembangan dan masa depan anak. Bila tidak ditangani dengan baik dan benar, perilaku agresif dapat berdampak negatif pada kehidupan anak di kemudian hari.

Hudaniah (2009) bahwa gresif adalah tingkah laku individu yang ditujukan untuk melukai atau mencelakakan individu lain yang tidak menginginkan datangnya tingkah laku tersebut. Sikap agresif anak pada usia dini jika menetap sampai anak tersebut dewasa, maka dampak yang sangat merugikan diri anak bila orangtua dan pendidik tidak dengan sungguh-sungguh mengatasi sikap anak karena tentunya sangat mempengaruhi masa depan anak tersebut. Setiap anak memiliki tumbuh dan kembang sesuai karakter perilaku yang dimiliki dan itupun berbeda-beda pada masing-masing anak. Bentuk perilaku agresif yang dimunculkan dari dalam dirinya berbeda dengan agresifnya temannya. Bentuk perilakunya misalnya, agresif verbal antara lain mengejek, berkata kotor. Sedangkan bentuk agresif non verbal atau fisik berupa serangan yang melukai temannya. Perilaku agresif tersebut harus segera diatasi, dan diusahakan agar tidak terlalu besar dampaknya sehingga dapat mempengaruhi kepribadiannya.
Salah satu pencegahan perilaku agresif pada anak Taman Kanak-Kanak adalah menggunakan metode pembelajaran role playing. Metode pembelajaran tersebut berupa teknik penyajian yang dikuasai oleh seorang guru untuk menyajikan materi pelajaran kepada murid di dalam kelas baik secara individual atau secara kelompok agar materi pelajaran dapat diserap, dipahami dan dimanfaatkan oleh murid dengan baik.

Berdasarkan permasalahan di atas, maka peneliti tertarik untuk melakukan penelitian tentang "Pengaruh Metode Role Playing dalam Mengurangi Perilaku Agresif Anak Kelompok B di TK Budhi Luhur Rumbai Pekanbaru.”

\section{METODE}

\section{Desain Penelitian}

Desain penelitian adalah semua proses yang diperlukan dalam perencanaan dan pelaksanaan penelitian. Desain penelitian yang digunakan adalah the one group pretest-posttest design. The one group pretest-posttest design adalah penelitian pre-eksperimen karena masih terdapat variabel luar yang ikut berpengaruh terhadap terbentuknya variabel dependen. Jadi hasil eksperimen yang merupakan variabel dependen itu bukan semata-mata dipengruhi oleh variabel independen. Hal ini dapat terjadi, karena tidak adanya variabel kontrol Sugiyono (2016) 


\section{Populasi}

Arifin (2011) mengemukakan populasi atau universe adalah keseluruhan objek yang di teliti, baik berupa orang, benda, kejadian, nilai maupun hal-hal yang terjadi. Populasi dalam penelitian ini adalah anak TK Budhi Luhur Rumbai Pesisir Kota Pekanbaru, yaitu pada kelompok kelas B yang terdiri dari satu kelas terdiri dari 16 anak.

\section{Sampel}

Teknik pengambilan sampel dalam penelitian ini yaitu dengan cara Total Sampling yaitu sampel dipilih secara keseluruhan dari populasi mempunyai peluang untuk menjadi anggota sampel (Arifin, 2011).

\section{Alat Pengumpulan Data}

Dalam sebuah penelitian diperlukan prosedur untuk mengumpulkan data. Kegiatan yang dilakukan oleh peneliti ialah dengan melakukan persiapan terlebih dahulu yaitu untuk menyiapkan istrumen penelitian, kemudian pelaksanaan penelitian dan penyelesaian. Tahap ini bermanfaat agar pada saat pengumpulan data berlangsung tidak terjadi hal-hal yang dapat menghambat proses penelitian. Adapun kegiatan dalam taap ini adalah:

a. Persiapan, yaitu tahap peneliti menyiapkan instrumen penelitian berupa (pretest dan posttest) sesuai dengan rumusan tujuannya.

b. Pelaksanaan, yaitu dengan mengumpulkan data dilakukan sebanyak 5 kali dengan diberikan pretest terlebih dahulu kemudian pemberian perlakuan, dan terakhir diberi posttest.

c. Pengolahan Data, yaitu data tes yang dikumpulkan kemudian di olah menggunakan penghitungan statistik dengan alat berupa program SPSS 17.0

d. Penyelesaian, yaitu tahap akhir untuk menuntaskan sebuah karya ilmiah.

\section{Analisis Data}

Sugiyono (2009) Analisis data merupakan kegiatan setelah data dari seluruh responden atau sumber data lain terkumpul. Kegiatan dalam menganalisis data adalah mengelompokkan data berdasarkan variabel dan jenis responden, menyajikan data tiap variabel yang diteliti, melakukan perhitungan untuk menjawab rumusan masalah, dan melakukan perhitungan anak menguji hipotesis yang telah diajukan. Untuk menguji hipotesis digunakan uji statistik, pengujian hipotesis, tersebut digunakan uji t. Uji hipotesis menggunakan uji $\mathrm{t}$ pada taraf kepercayaan $95 \%$ atau $\alpha=0,05$ dengan menggunakan SPSS windows ver.17.0. Dengan skala likert, maka variabel yang akan diukur dijabarkan menjadi indikator variabel. 


\section{HASIL DAN PEMBAHASAN}

Grafik Presentasi Perilaku Agresif

Kelompok B di TK Budhi Luhur

Sebelum Perlakuan (Pretest)

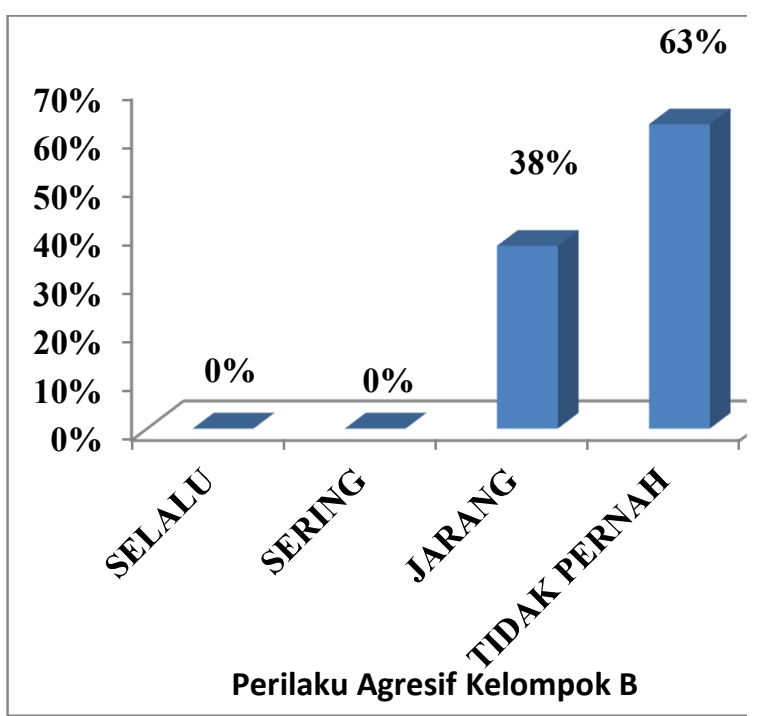

Berdasarkan gambar : grafik presentase diatas bahwa presentase yang diperoleh dengan kategori anak Selalu (SL) terhadap perilaku agresif Kelompok B sebesar 0\%, kategori Sering (SR) terhadap terhadap perilaku agresif Kelompok B sebesar 0\%, kategori Jarang (JR) terhadap terhadap perilaku agresif Kelompok B sebesar 37,5\% dan kategori Tidak Pernah (TP) terhadap perilaku agresif Kelompok B sebesar 62,5\%.

\section{Grafik Presentasi Perilaku Agresif \\ Kelompok B di TK Budhi Luhur \\ Sesudah Perlakuan (Posttest)}

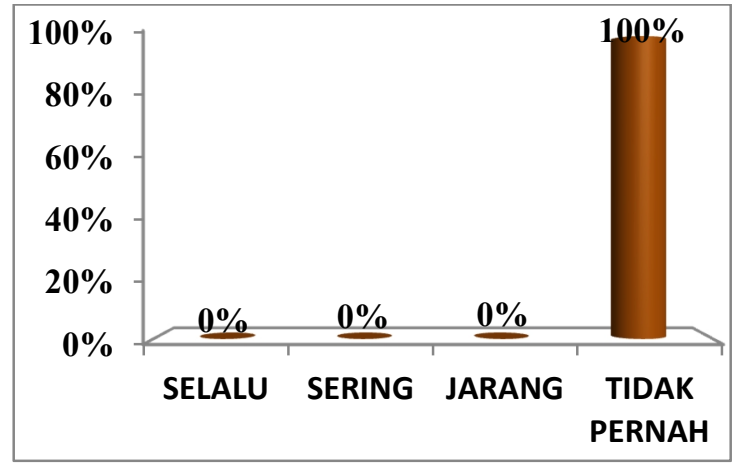

Berdasarkan gambar : grafik presentase diatas bahwa presentase yang diperoleh dengan kategori anak Selalu (SL) terhadap perilaku agresif Kelompok B sebesar 0\%, kategori Sering (SR) terhadap terhadap perilaku agresif Kelompok B sebesar 0\%, kategori Jarang (JR) terhadap terhadap perilaku agresif Kelompok B sebesar 0\% dan kategori Tidak Pernah (TP) terhadap perilaku agresif Kelompok B sebesar $100 \%$.

Perbandingan Hasil Pretest dan Posttest

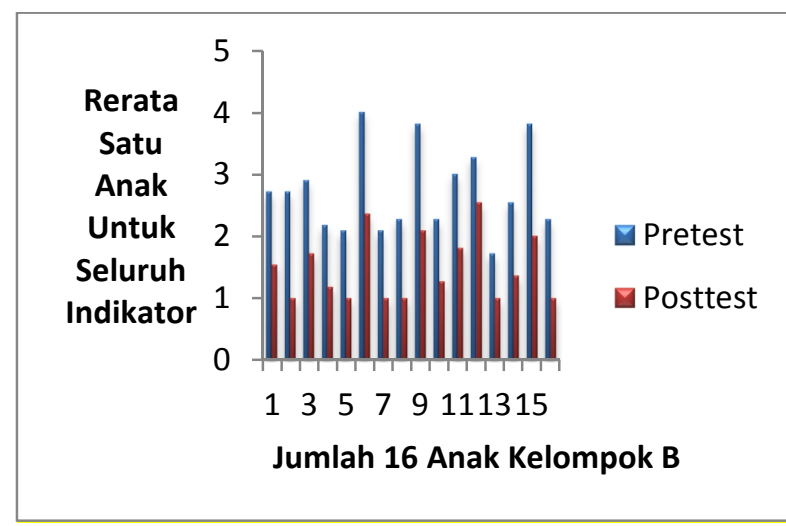

Berdasarkan gambar diatas bahwa persentase yang diperoleh 6 adanya pengaruh metode role playing antara sebelum perlakuan (Pretest) dan sesudah perlakuan (Posttest). Hasil diolah dari lembar observasi dan 
Tabel Hasil Uji Hipotesis

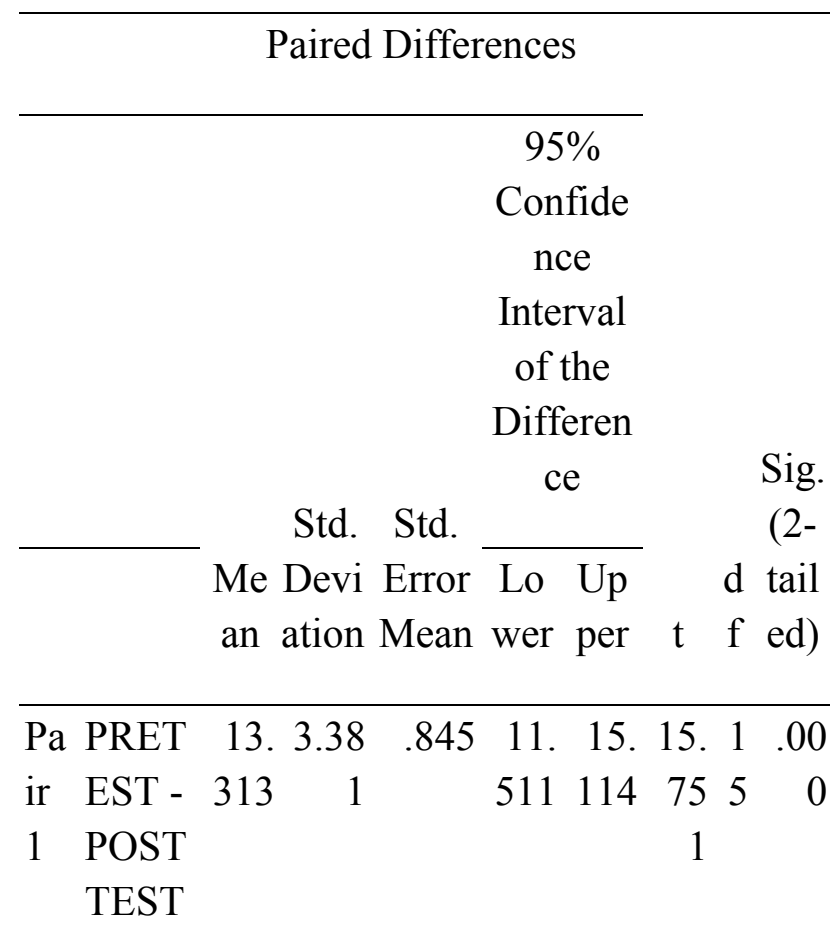

distribusi ke Ms.Excell 2010, untuk mendapatkan rerata pretest dan posttest dengan cara masing-masing anak untuk seluruh indikator sehingga terdapat pengaruh yang signifikan dari pretest posttest untuk perilaku agresif anak kelompok B TK Budhi Luhur Rumbai Pekanbaru.

Setelah melakukan analisis data, langkah selanjudnya yaitu menguji hipotesis.Pengujian hipotesis dalam penelitian ini menggunakan metode ttest dengan bantuan program SPSS Windowst 17.0 untuk melihat perbedaan pada sebelum dan metode role playing untuk mengurangi perilaku agresif. Data dikatan mengalami penigkatan yang signifikan jika $\operatorname{sig}(2$ tailed $)<0.05$. jika sig $>0,05$ maka $\mathrm{H}_{0}$ diterima, Ha ditolak dan sebaliknya jika sig $<0,05$ maka Ha diterima, $\mathrm{H}_{0}$ ditolak. Hal ini juga dapat dilihat pada nilai lower dan upper, jika lower dan upper bernilai negatif maka $\mathrm{Ha}$ diterima dan $\mathrm{H}_{0}$ ditolak, jika lower dan upper bernilai positif maka $\mathrm{H}_{0}$ diterima dan $\mathrm{Ha}$ ditolak. (Sundayana, 2014: 23).

Ha: Tidak Terdapat penigkatan yang signifikan terhadap perilaku agresif anak setelah melakukan metode role playing.

$\mathrm{H}_{0}$ : Terdapat peningkatan yang signifikan terhadap perilaku agresif anak setelah penerapan metode role playing

Tabel 7 menunjukkan perolehan uji statistik dengan hasil thitung $=$ 15.751 uji dua pihak berarti harga mutlak, sehingga $t_{\text {hitung }} 15.751$ ttabel 1,753 , dengan nilai df yaitu 15 pada taraf 0,05 . Nilai tersebut menunjukkan perubahan yang signifikan terlihat dari nilai sig ( 2 tailed) sebesar 0,000 . Nilai sig $0,000<0,05$ atau nilai sig kecil dari 0,05 , dengan demikian $\mathrm{H}_{\mathrm{a}}$ diterima dan $\mathrm{H}_{0}$ diolak. Artinya perbedaan nilai sesudah perlakuan mengalami peningkatan yang signifikan. Hal ini juga dibuktikan dengan nilai lower dan supper yang bertanda negatif. Dengan kata lain, metode role playing berpengaruh terhadap mengurangi perilaku agresif.

\section{KESIMPULAN}

Berdasarkan hasil penelitian dapat disimpulkan bahwa:

a. Pengaruh metode role playing dalam menguragi perilaku agresif anak Kelompok B Tk Budhi Luhur 
Rumbai Pekanbaru, masing-masing anak sebelum diberikan perlakun yaitu kategori Selalu (SL) terhadap perilaku agresif Kelompok B sebesar 0\%, kategori Sering (SR) terhadap terhadap perilaku agresif Kelompok B sebesar 0\%, kategori Jarang (JR) terhadap terhadap perilaku agresif Kelompok B sebesar 37,5\% dan kategori Tidak Pernah (TP) terhadap perilaku agresif Kelompok B sebesar 62,5\%. Selanjutnya, hasil setelah diberi perlakuan (treatment) perilaku agresif anak mengalami penurunan perilku agresif yang signifikan yaitu kategori anak Selalu (SL) terhadap perilaku agresif Kelompok B sebesar 0\%, kategori Sering (SR) terhadap terhadap perilaku agresif Kelompok B sebesar 0\%, kategori Jarang (JR) terhadap terhadap perilaku agresif Kelompok B sebesar 0\% dan kategori Tidak Pernah (TP) terhadap perilaku agresif Kelompok B sebesar 100\%. perolehan uji statistik dengan hasil $\mathrm{t}_{\text {hitung }}=15.751$ uji dua pihak berarti harga mutlak, sehingga $t_{\text {hitung }} 15.751$ ttabel 1,753, dengan nilai df yaitu 15 pada taraf 0,05 . Nilai tersebut menunjukkan perubahan yang signifikan terlihat dari nilai sig (2 tailed) sebesar 0,000. Nilai sig $0,000<0,05$ atau nilai sig kecil dari 0,05 , dengan demikian $\mathrm{H}_{\mathrm{a}}$ diterima dan $\mathrm{H}_{0}$ diolak. Artinya perbedaan nilai sesudah perlakuan mengalami peningkatan yang signifikan. Hal ini juga dibuktikan dengan nilai lower dan supper yang bertanda negatif. Dengan kata lain, metode role playing berpengaruh terhadap mengurangi perilaku agresif.

Berdasarkan hasil penelitian yang diperoleh, maka penulis akan memberikan beberapa saran yang dapat dijadikan masukan bagi pihak-pihak yang terkait didalam ruang lingkup PAUD. Adapun saran tersebut adalah :

a. Bagi Sekolah Diharapkan sekolah mendukung kegiatan bermain peran dan diadakan di setiap tema, agar anak tidak mudah bosan dalam proses belajar mengajar dikelas dan sekolah mendukung dengan media dan fasilitas agar terlaksananya metode role playing.

b. Bagi Guru

Diharapkan guru dapat mengetahui apa yang dinginkan anak pada saat belajar menyiapkan dan milih metode role playing dalam mengurangi perilaku agresif anak dikelas.

c. Bagi Peneliti Selanjutnya

Meneliti secara lebih mendalam tentang pengaruh metode role playing dalam mengurangi perilaku agresif Kelompok B di TK Budhi Luhur guna meningkatkan kualitas sumber data manusia untuk masa yang akan datang.

\section{DAFTAR PUSTAKA}

[1] Arifin, Z. 2011. Penelitian Pendidikan. Bandung: Remaja Rosdakarya. 
[2] Dewi, E. 2014. Upaya Mengatasi Munculnya Tingkah Laku Agresif Anak Melalui Mendengarkan Cerita Di Kelompok B Tk Aba Tegal Domban Tempel Sleman. Yogyakarta. UNY

[3] Fatmawati, A. 2014. Pengaruh Aktivitas Menggambar Terhadap Perilaku Agresif Anak Usia 3-6 Tahun di PAUD Sariharjo Ngagik Sleman. Yogyakarta. STKIA.

[4] Harvityanto, M. 2013. Pengertian hipotesis. Jakarta: Rineka Cipta.

[5] Kunandar. 2008. Metode Penelitian. Jakarta: Bumi Aksara.

[6] Meinarno, E. 2009. Psikologi Sosial. Jakarta: Salemba Humanika.

[7] Miftahul, H. 2014. Model-Model Pengajaran dan Pembelajaran.Yogyakarta: Pustaka Belajar.

[8] Wirawan. 2009.Evaluasi Kinerja Sumber Daya Manusia Teori Aplikasi dan Penelitian. Jakarta: Salemba Empat.

[9] Zain, A. 2006. Strategi Belajar Mengajar. Jakarta: PT Rineka Cipta.

[10] Zirpoli, T.J. 2008. Behavior Management: Application For Teacher. New York: Pearson Allyn Bacon Prentice Hall. 